phrases), or instructions as to what learners are expected to do with the conversations in section 2, as you may expect in intermediate and advanced Japanese language textbooks. Therefore, using this textbook in Japanese language classes may require instructors to be proficient in content-based instruction. Depending on the level and interest of students, the book can introduce a variety of topics and engaging tasks for an upperlevel, content-based language classroom.

In sum, $J U C$ is an excellent textbook of nihon jijo for learners of Japanese at upper-intermediate and advanced proficiency, suitable for the classroom or for independent study. Ample visual aids make even sophisticated topics accessible. Learners will benefit from performing different tasks introduced throughout the volume to explore and investigate Japanese culture on their own, to interact with their classmates and with people outside of the classroom, and to make presentations about their findings.

\title{
Residual Futures: The Urban Ecologies of Literary and Visual Media of 1960s and 1970s Japan
}

By Franz Prichard. New York: Columbia University Press, 2019. 268 pp. + x. Paperback, \$35.00.

\section{Reviewed by Atsuko Sakaki}

This book is ambitious and exuberant—not so much in its scope (which is highly selective and specialized) as in its urgent and earnest call for a conversation between diverse intellectual inquiries, from urban studies to literary studies to media studies. Prichard gives uninhibited voice to social and political problems to which we have been alerted by many intellectuals of our time, such as the inequality, banality, and precarity of lives lived in late capitalist urban space, as visually and textually mediated, as well as to the critical discourse that engages with these registers. As the book proceeds in addressing these current issues, the reader hears a chorus of other thinkers as well, some of whom it foregrounds more than others.

Framing its immediate referents historically and geopolitically, as stipulated in its subtitle, the book complicates temporality. The primary sources - film, fiction, photography, and essays on them - that Prichard discusses have both addressed results of the then recent past political crises

Japanese Language and Literature $\mid$ jll.pitt.edu

Vol. 54 | Number 1 | April 2020 | DOI: https://doi.org/10.5195/j1l.2020.144 
and anticipated the then new visions and methods of cinematic, literary, and photographic narrative formation, while outcomes of these initiatives are now characterized as traces of their forward-looking future-oriented projects. The main title, Residual Futures, should thus be taken in two senses: (1) futures envisioned by topical artists and writers active in the 1960s and 1970s as residues of their recent past, and (2) residues of their anticipations of the future recognized as such in the present of our early twenty-first century. The title (which may at first glance sound tautological) is, then, deliberately loaded and conceptually elaborate. The bilateral vectors, evident in these two interfaces of anticipation and remembrance and appropriate for the archeological procedure, inform the chapters under the title. The book's subtitle, Urban Ecologies, suggests another node of intensity, namely, space. Instead of narrating space chronologically, this book illustrates time as manifested in space-or, more precisely, time as highlighted in visual and textual formation of space - through the experiences of itinerant observers such as a taxi driver, a homeless person, and a street photographer. Their mobility, instability, and susceptibility to environmental changes coordinate the interface of spatiality and temporality.

The range of the corpus is well warranted, and though each chapter focuses on one individual (artist, novelist, critic), Prichard signals toward instances of relevance in other chapters, making the book cohesive and enabling the reader to weave a narrative beyond the order of contents. The three main characters indeed share critical concerns, echoing if not crossreferencing each other: the documentary film director Tsuchimoto Noriaki (1928-2008) in chapter 1, the novelist/screen writer/playwright/critic Abe Kōbō (1924-93) in chapter 2, and the photographer and photo critic Nakahira Takuma (1938-2015) in chapters 3 to 5. Tsuchimoto's films such as Dokumento Rojō (On the road: A document, 1964), which Prichard focuses on, have been well known since their original release and have attracted much critical attention in recent years. Abe's statureestablished by many critical books in Japanese, English, and other languages, translations in multiple languages, and extensive output in theatre, cinema, and photography_-goes without saying, with Moetsukita chizu (1967; trans., A Ruined Map, 1969) and Hako otoko (1973; trans., The Box Man, 1974), the novels Prichard discusses at length, being among Abe's most representative works. Nakahira is one of the legendary photographers and photo critics in the history of the medium in Japan, known for his prolific output. His photographs and essays on photography have been published in monographs such as Kitarubeki gengo no tame ni

Japanese Language and Literature $\mid$ jll.pitt.edu

Vol. 54 | Number 1 | April 2020 | DOI: https://doi.org/10.5195/j11.2020.144 
(For a language to come, 1970), Naze shokubutsu zukan ka (Why an illustrated botanical dictionary?, 1973), Hanran (Overflow, 1974; 2018), Sākyurēshon: hizuke, basho, kōi (Circulation: Date, place, events, 1971; 2012), and Okinawa Amami Tokara 1974-1978 (2012). His international acclaim is attested to in his inclusion in major reference books on (Japanese) photography, such as Ryūichi Kaneko and Ivan Vartanian, eds., Japanese Photobooks of the 1960s and 1970s (Aperture, 2009). Around these central figures, who led visual and textual media of their time, are a few less celebrated yet comparable and highly relevant visionaries, such as the writer, artist, and performer Terayama Shüji (1935-83) and the activist Tanigawa Gan (1923-95), whom Prichard introduces primarily because of their respective collaborations with one of the three major figures. The cast is legitimate, if limited (more on this later).

The book is outstanding in its close reading of cinematic scenes and sequences, narrative passages, and framed photographs. Prichard illuminates the significance of vernacular landscape and banal proceedings that might otherwise elude the viewer/reader, patiently enlightening his audience as he takes us through noteworthy portions of the sources. After all, these artists/writers are masters of their arts, and would not neglect to refine the details of their output - and their strategic compositions of scenes in their respective discourses deserve as insightful a viewer/reader as Prichard. Thus, in chapter 1, he explicates how the intricate camerawork in Tsukamoto's film unfolds a sequence loaded with variable angle, pace, and texture:

Finally breaking free of downtown traffic, the taxi accelerates as it crosses a long bridge heading out of town. An establishing shot briefly fixes the viewers' gazes on a static landscape across the river, where the densely packed roofs of a residential district are woven together with antennae and tall towers carrying power lines, before plunging viewers into the district's narrow streets, where we are confronted with layer upon layer of laundry hung out to dry. The taxi carefully passes through the densely packed main street of the residential neighborhood, and the camera makes a sweeping survey of the potential hazards (children, dogs, bikes, and pushcarts) before embedding itself in a lowangle view from the front of the taxi as it charges forward.... These details of the intimate domestic domain played out in the streets are interrupted as the taxi turns off the busy strip to follow after a pair of skating youths through a narrow alleyway, lined with older wooden homes. There, the camera-taxi's forward motion comes to an abrupt stop, confronting the looming form of a large stadium. A static reverse shot of the stadium where a piece of paper slowly floats around on the

Japanese Language and Literature $\mid$ jll.pitt.edu

Vol. 54 | Number 1 | April 2020 | DOI: https://doi.org/10.5195/j1l.2020.144 
breeze in the empty parking lot marks the end of the taxi's passage through the residential area. The monolithic stadium, empty and distinctly at odds with the immediate surroundings, poses a telling contrast of worlds. In the taxi's passage among the diverse uses and multifunctional microcosm of the residential neighborhood's streets and alleys, an uncanny threshold is revealed in the barren, spectacular macroscopic expanse of the stadium's concrete walls and ramps. (4041)

And in chapter 5, Prichard articulates the grammar of photography as it operates effectively in a printed image by Nakahira:

For instance, take the graveyard photograph in the Asahi Camera installment. The sharply focused photograph captured the cleanly piled stones of the low walls that divided the grave plots, receding on a steep incline that drew the viewer's gaze toward the horizon where the blue sky and downy clouds lingered over the varied patterns of stones and graves woven with wild grasses and plants. The subtly cropped printed photograph obtained a kind of symmetry between upper and lower halves of a picture plane that was evenly divided, neatly splitting the foreground and background. However, more than an ethnographic document of burial practices that could support the evidentiary value of the invisible zone of cultural differences that Nakahira indexed as the objective of his text, we encounter a vivid enumeration of material boundaries, both within the photographic frame and of the photographic framing itself. That is, the split plane delineated not only the details of the piled stone walls and graves, but also elaborated a matrix of tensions that set the gaze of the viewer at odds with the photographed subject matter. For the juxtapositions wrought by the perpendicular orientation of the foreground abutting with the horizontals of the receding walls of the upper background suspended the vertical movement of the viewer's gaze while inviting it to consume - and be consumed by - the proliferation of details, resplendent and yet devoid of immediately legible meanings. (168)

Rather than becoming consumed by the narrative flow, plot, or package that is often considered to be formative of cinema, fiction, and photography, Prichard ably alerts the reader's attention to the surface of the screen and the periphery of the frame, which are never irrelevant in the deliberate manipulation and evocation of the materiality of the media for which these three masters are known.

As indicated above, this book attempts an historical overview of these key figures' respective works, which also invites further genealogical or comparative considerations of other artists, writers, and thinkers. A

Japanese Language and Literature $\mid$ jll.pitt.edu

Vol. 54 | Number 1 | April 2020 | DOI: https://doi.org/10.5195/j11.2020.144 
particularly thrilling prospect that this book opens for us is to carve out Nakahira's singularity over or commonality with other photographers with whom he shared social and political conditions, aesthetic visions, and technical procedures. Prichard rightly situates him vis-à-vis Moriyama Daidō, a Provoke artist often compared with him in chapter 3; Taki Kōji, an outstanding Provoke theorist and practitioner in his own right, whose seminal works are engaged with throughout chapters 3 to 5; and Tōmatsu Shōmei, who is effectively taken into comparative and historical consideration in chapter 5 . This tempts me to think that a comparison between Nakahira and Fukase Masahisa (1934-2012) would be highly productive, since Fukase not only explored the space of banality with his camera but also shared Nakahira's fate of paralysis (corporeal vulnerability of the artist to the space he/she navigates and captures). Similarly, consideration of Miyamoto Ryūji (b. 1947), a younger photographer of similar subject matter-such as homeless people in cardboard boxes, southern islandic ecology, and dystopic metropolitan cityscape - may be a legitimate extension of chapter 6, in which Prichard overviews some later photographers' aesthetic and political stances.

Theoretical literatures are engaged as expected in such a conceptually oriented book in order to situate it within a larger context. Walter Benjamin, Paul Virilio, and Maeda Ai are among the handful of theoretical lynchpins. Prichard introduces their fundamental questions and formative insights with fluidity and energy, demonstrating his mastery of their theories. It would be desirable to explicitly cite more theorists, rather than letting them hover phantasmagorically. Thus, we almost hear the pulsation of Lefebvrian rhythmanalysis in chapters 1 and 2, although we don't see Henri Lefebvre's name printed there. By the same token, David Harvey's critique of socio-economic conditions of urban space may be fundamental for the book in its entirety. Susan Sontag is never called upon, though her seminal works on visual media - On Photography and Regarding the Pain of Others - may have been on Prichard's mind, as they would perfectly fit the discussion of photography as the print mass media in chapter 3 . Similarly, in chapter 5, some readers might recall Allan Sekula's take on documentary photography. Their echoes may or may not have been intended, yet Residual Futures is assured a place in the company of such seminal theoretical works.

As far as scholarship in Japan studies is concerned, the way Prichard seeks to claim a stake in it is noteworthy. Instead of the conventional style of a literature review, identification of gaps in the existing scholarship, and a statement of the plan to fill some of them, Prichard draws a firm line

Japanese Language and Literature $\mid$ jll.pitt.edu

Vol. 54 | Number 1 | April 2020 | DOI: https://doi.org/10.5195/j1l.2020.144 
between his own argumentation (in the main body of the text) and relevant scholarly works (introduced almost exclusively in the endnotes). This is a conscious decision, as stated in the first sentence of the Acknowledgments: "The extensive notes at the end of this volume offer a partial mapping of the intellectual genealogies at play in these chapters" (vii). This alerts the reader that the endnotes should not be neglected. Indeed, Prichard's references to scholarly precedents encapsulate his peers' respective contributions to the field in a few lines, respectfully and adequately. I would like to comment on a few who could have been more squarely engaged with.

Philip Charrier, who is arguably the leading scholar of twentiethcentury Japanese photography, is only mentioned in one endnote, without any entry in the index. This passing reference is to Charrier's article in Japan Forum (2017) on Nakahira's Naze shokubutsu zukan ka. There are others by the same scholar that are equally relevant to Prichard's book: an article in History of Photography (2017) on Taki Kōji and the magazine Provoke, in which Nakahira is extensively discussed (citing Prichard's dissertation, on which Residual Futures is based); and an article in History of Photography (2010) on another important Japanese photographer, Moriyama Daidō, in which Terayama Shūji, a literary figure discussed in chapter 3 of Prichard's book, is a central focus. Charrier's approach is meticulously and solidly art historical, with numerous citations of sources and images, and thus is distinct from Prichard's, which is anchored in provocations of geopolitical polemics. Despite the methodological disparity, further engagement with Charrier's work would promise to be productive.

Another predecessor that could be cited is Provoke: Between Protest and Performance: Photography in Japan 1960-1975, edited by Diane Dufour and Matthew S. Witkovsky (Steidl, 2016), a collaborative volume of essays on the eponymous movement/journal. Perhaps due to its recent publication, this volume may have eluded Prichard's attention. I would suggest that readers of Residual Futures also consult this volume because the two complement each other.

Jonathan Reynolds's Allegories of Time and Space: Japanese Identity in Photography and Architecture (University of Hawai'i Press, 2014) is probably the closest comparison to Residual Futures in content and concept (mediation of time and space in visual and textual registers). However, it is only mentioned in two endnotes, with respect to Reynolds's chapter on the photographer Tōmatsu Shōmei's representation of Okinawa, which serves as a prelude to Nakahira's output from the same locale.

Japanese Language and Literature $\mid$ jll.pitt.edu

Vol. 54 | Number 1 | April 2020 | DOI: https://doi.org/10.5195/j11.2020.144 
Reynolds in fact explicates Abe Kōbō's The Box Man, in terms of its urban space/visuality nexus, which is a subject of Prichard's chapter 4. Thus, more extensive engagement with Reynolds's work would be desirable.

On a more technical note, Japanese titles/terms are often not represented, even when there is no existing translation or established English equivalent; instead, only their approximate English translation is provided in the main body, the notes, or the index. Readers would benefit from being able to look further into such sources with the citation of original titles and terms, at least in their first appearance in the volume. It would also be highly desirable to correlate reprinted images with applicable passages in which they are closely and insightfully explicated (as, for example, on pages 168 and 186), so that readers could collate the two mediums point by point, verifying the author's argument. There should also be a list of illustrations and a list of copyright owners (only the cover photo is credited in full, on the back cover).

Residual Futures addresses timely critical issues that many of us share and has succeeded in creating a network of considerations across premeditated disciplines. With its examinations of documentary film, which is by default multimedia, and of visually oriented authors such as Abe and textually prolific artists such as Nakahira, this book will command attention from a wide range of scholars and other critically minded readers to urgent consideration of these registers, as well as of the urban space they formed and transformed. I congratulate the author on the wonderful beginning of what promises to be a long and productive journey.

\section{An Anthology of Kokugaku Scholars: 1690-1868}

By John R. Bentley. Ithaca, N. Y.: Cornell East Asian Series, 2017. x, 596 pp. $\$ 45.00$.

\section{Reviewed by \\ Clarence I-Zhuen Lee}

The importance of the Edo period movement called Kokugaku (lit. the study of the country) cannot be understated, from its appropriation by Mito domain scholars to renovate the decaying Tokugawa social order in the nineteenth century, to its usage in the ideology of the Japanese colonial empire in the 1930s and 1940s,

Japanese Language and Literature $\mid$ jll.pitt.edu

Vol. 54 | Number 1 | April 2020 | DOI: https://doi.org/10.5195/j11.2020.149 